\title{
Sintering of Incorporated Shape Memory Alloys into Functionally Graded Materials
}

\author{
Khafaji NSL ${ }^{1 *}$, Hafiz $\mathrm{MH}^{2}$ and Atiyah $\mathrm{AA}^{2}$
}

${ }^{1}$ Department of Metallurgy Engineering, Collage of Materials Engineering, Babylon University, Iraq

${ }^{2}$ Department of Materials Engineering, Technology University, Iraq

\begin{abstract}
Shape Memory Alloys (SMAs) have been investigated as one of the most full of promise smart materials in multi applications. Among the commercially obtainable Shape Memory Alloys, nickel-titanium (Nitinol or NiTi) ones are wonderful due to their outstanding performance and reliability. In addition to strain recovery, (Ni-Ti) be an attraction in several medical applications due to its biocompatibility, corrosion resistance and fatigue behavior. Low range of transition temperature was the main challenges in the fabrication of these materials. A novel method was introduced to improve the range of transition temperatures by incorporating the shape memory effect into functionally graded materials concept. Therefore, industrialization and implementing of NiTi functionally graded materials made by a powder metallurgy method were carried out through the current work. Two samples with different seven layers of NiTi/NiTi functionally graded materials were compacted using steel die and punch at the same compacted pressure and different sintered temperature. After inspect the different samples of NiTi/NiTi functionally graded materials under different fabrication conditions, the suitability fabrication regime was determined with the aid of microscopic observations. These materials are designed to have gradual or abrupt Microstructural or compositional variations within the body in one piece of material, these samples have been produced by powder metallurgy approach and the effect of composition for each layer studied on the XRD.
\end{abstract}

Keywords: SMA; Functionally graded NiTi materials; Biocompatibility; XRD

\section{Introduction}

Functionally graded materials (FGM) contain of a gradual change in the volume fraction or mechanical properties of the ingredient in a direction. Functionally graded materials are ideal for applications include sharp thermal gradients, ranging from thermal structures in advanced aircraft and aerospace engines to computer circuit boards [1]. The conception of Functionally Graded Materials (FGMs) was basically advanced in the early 1980s in Japan, where this new material notion was proposed to increase adhesion and minimize the thermal stresses in metallic-ceramic composites advanced for reusable rocket engines [2].

\section{Design of FGM}

A main problem in the design of an FGM, aside from this materials selection, lies in determining the optimum spatial dependence for the composition. This can be regarded by as that composition profile which best accomplishes the intended purpose of the material while preserve other thermal, physical, and mechanical properties within limits that ensure favorable performance. Another problem lies in prophesy the characteristics of an FGM, for a given composition profile, during manufacturing and under in service conditions. Use of theoretical models to aid in FGM design and to predict FGM fabrication and inservice behavior is of crucial importance. Once decided, a model can readily be used to conduct a wide variety of computer "experiments" in which effects of changing input parameters, such as thermo physical properties of the constitutive phases, or the composition profile along the graded direction, is systematically evaluated [3].

The fact that the composition of an FGM cans vary over such a wide range means that a variety of fundamentally different microstructures can exist across the graded direction. This, in turn, means that the thermo physical properties, which are generally substantially dependent on the microstructure, will also vary with position within the material.
A realistic model must appropriately enough account for this fact. According to the FGM model, the dimensions and composition of each layer will be determined using the following formula [4]:

$$
\mathrm{V} 1(\mathrm{x})=\left(\frac{(\mathrm{X} 2-\mathrm{X})}{(\mathrm{X} 2-\mathrm{X} 1)}\right)^{\mathrm{N}}
$$

Where, V1 (x) represents the local volume fraction of $\mathrm{Ni}$, while the volume fraction of $\mathrm{Ti}$ is being according to the formula:

$$
\mathrm{V} 2(\mathrm{x})=1-\mathrm{V} 1(\mathrm{x}) \mathrm{X} 1
$$

$\mathrm{X}_{1}$ and $\mathrm{X}_{2}$ are the border regions of pure $(\mathrm{NiTi})$ and $(\mathrm{NiTi})$ respectively, $(\mathrm{N})$ is a variable parameter, where its magnitude determines the curvature of $\mathrm{V}_{1}(\mathrm{x})$. The solution of equations above at different values of $\mathrm{N}$ (i.e., 1,2 and 0.5 ) is represented schematically in the following figure and curve.

With higher values of $(N)$ the plate tends to be toward layer 1 and 7 (the lower and upper layers) that lower values of $(N)$ tend toward layer 4 (the core layer) (Figure 1). Designers can vary the $(N)$ value to tailor made the FGM to specific applications at $N=0$, the curve would really be a vertical line corresponding to a volume fraction of layer $7=1$. Additionally higher values of $(N)$ push the curve toward layer 1 and 7. At $N=\infty$, a straight line would stay at a layer 1 and 7 volume fraction of 0 indicate layer 4 It is apparent that structural designers requiring

*Corresponding author: Khafaji NSL, Department of Metallurgy Engineering, Collage of Materials Engineering, Babylon University, Iraq, Tel: 7801006256 E-mail:dr.nabbaa@gmail.com

Received November 23, 2017; Accepted December 28, 2017; Published January 08, 2018

Citation: Khafaji NSL, Hafiz MH, Atiyah AA (2018) Sintering of Incorporated Shape Memory Alloys into Functionally Graded Materials. Ind Eng Manage S3: 002. doi: 10.4172/2169-0316.S3-002

Copyright: (c) 2018 Khafaji NSL, et al. This is an open-access article distributed under the terms of the Creative Commons Attribution License, which permits unrestricted use, distribution, and reproduction in any medium, provided the original author and source are credited. 
Citation: Khafaji NSL, Hafiz MH, Atiyah AA (2018) Sintering of Incorporated Shape Memory Alloys into Functionally Graded Materials. Ind Eng Manage S3: 002. doi: 10.4172/2169-0316.S3-002

Page 2 of 4

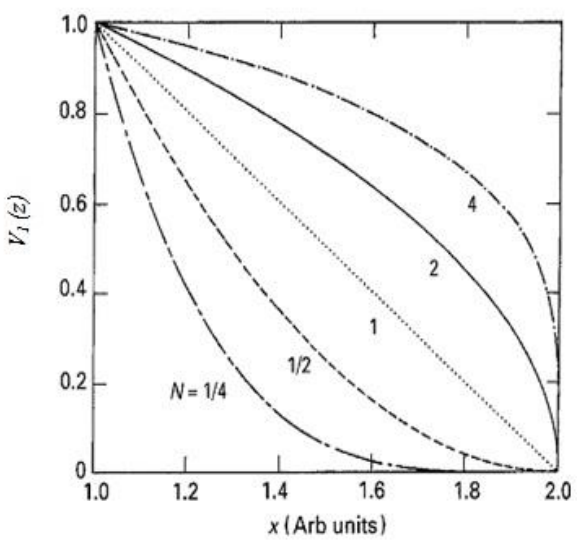

Figure 1: Plot of $V_{1}(\mathrm{z})$ vs. $\mathrm{Z}$ (eqn. 1) for selected values of $\mathrm{N}$

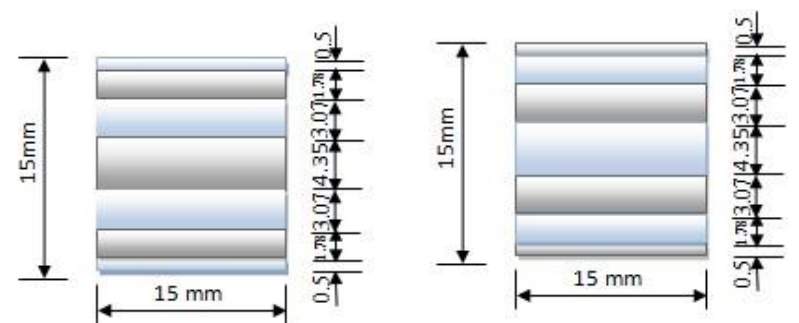

Figure 2: Design of seven layers SMA-FGMs: (a) SMA-FGM , (b) SMA-FGM

\begin{tabular}{|c|c|c|}
\hline Layers & Chemical composition & Thickness $(\mathbf{m m})$ \\
\hline $\mathbf{1}^{\text {st }}$ & $50 \%$ at Ti-50\%at $\mathrm{Ni}(45 \%$ wt Ti-55\% wt Ni) & 0.5 \\
\hline $\mathbf{2}^{\text {nd }}$ & $49.3 \%$ at Ti-50. $\%$ at $\mathrm{Ni}(44.2 \%$ wt Ti-55.8\% wt Ni) & 1.78 \\
\hline $3^{\text {rd }}$ & $48.5 \%$ at Ti-51. $5 \%$ at $\mathrm{Ni}(43.5 \%$ wt Ti-56.5\% wt Ni) & 3.07 \\
\hline $\mathbf{4}^{\text {th }}$ & $47.8 \%$ at Ti-52. $\%$ at $\mathrm{Ni}(42.7 \%$ wt Ti-57.3\% wt Ni) & 4.35 \\
\hline $\mathbf{5}^{\text {th }}$ & $48.5 \%$ at Ti-51. $5 \%$ at Ni $(43.5 \%$ wt Ti-56.5\% wt Ni) & 3.07 \\
\hline $\mathbf{6}^{\text {th }}$ & $49.3 \%$ at Ti-50.7\%at Ni $(44.2 \%$ wt Ti-55.8\% wt Ni) & 1.78 \\
\hline $7^{\text {th }}$ & $50 \%$ at Ti-50\%at Ni $(45 \%$ wt Ti-55\% wt Ni) & 0.5 \\
\hline
\end{tabular}

Table 1: Model of SMA-FGM 1 profile.

important thermal protection should consider low values of $(N)$ which will yield layer 4 . Designers that wish corrosion protection with high load carrying capability should belive higher values on $(N)$ which yield layer 1 and 7 [5].

In the present work, $(N)$ is taken as 1 as model special distribution of SMA-FGM. As shown in Figure 2; the model has $(15 \mathrm{~mm})$ length and $(15 \mathrm{~mm})$ diameter, for $z_{1}=(0.5 \mathrm{~mm})$ thickness of layer $1, z_{2}=(4.53 \mathrm{~mm})$ thickness of medium layer and the graded layers lies between them.

\section{Fabrication and Characterization}

The elemental powders used in this study to prepare (SMA-FGMs) layers with an average particle size as $33 \mu \mathrm{m}$ for Nickel powder and 165 $\mu \mathrm{m}$ for Titanium powder. Preparation of SMA-FGM layers according to pre designed model profile as indicated in Tables 1 and 2 includes; wet mixing of the powders for $(7 \mathrm{~h})$, filling of powders into the die cavity by stepwise controlled manner, compacting of powders with pressure at $(300 \mathrm{MPa})$. Sintering of all prepared samples was in vacuum furnace with Argon inert gas to $(7 \mathrm{~h}$. $)$ at $\left(950^{\circ} \mathrm{C}\right)$. X-ray diffraction used extensively to ensure the development of Martensitic phases during sintering.

Phase's analysis of prepared alloys is based upon X-ray diffraction

\begin{tabular}{|c|c|c|}
\hline Layers & Chemical composition & Thickness (mm) \\
\hline $1^{\text {st }}$ & $47.8 \%$ at $\mathrm{Ti}-52.2 \%$ at $\mathrm{Ni}(42.7 \%$ wt $\mathrm{Ti}-57.3 \%$ wt $\mathrm{Ni})$ & 0.5 \\
\hline $2^{\text {nd }}$ & $48.5 \%$ at $\mathrm{Ti}-51.5 \%$ at $\mathrm{Ni}(43.5 \%$ wt $\mathrm{Ti}-56.5 \%$ wt $\mathrm{Ni})$ & 1.78 \\
\hline $3^{\text {rd }}$ & $49.3 \%$ at $\mathrm{Ti}-50.7 \%$ at $\mathrm{Ni}(44.2 \%$ wt $\mathrm{Ti}-55.8 \%$ wt $\mathrm{Ni})$ & 3.07 \\
\hline $4^{\text {th }}$ & $50 \%$ at $\mathrm{Ti}-50 \%$ at $\mathrm{Ni}(45 \%$ wt $\mathrm{Ti}-55 \%$ wt $\mathrm{Ni})$ & 4.35 \\
\hline $5^{\text {th }}$ & $49.3 \%$ at $\mathrm{Ti}-50.7 \%$ at $\mathrm{Ni}(44.2 \%$ wt $\mathrm{Ti}-55.8 \%$ wt $\mathrm{Ni})$ & 3.07 \\
\hline $6^{\text {th }}$ & $48.5 \%$ at $\mathrm{Ti}-51.5 \%$ at $\mathrm{Ni}(43.5 \%$ wt $\mathrm{Ti}-56.5 \%$ wt $\mathrm{Ni})$ & 1.78 \\
\hline $7^{\text {th }}$ & $47.8 \%$ at $\mathrm{Ti}-52.2 \%$ at $\mathrm{Ni}(42.7 \%$ wt $\mathrm{Ti}-57.3 \%$ wt $\mathrm{Ni})$ & 0.5 \\
\hline
\end{tabular}

Table 2: Model of SMA-FGM2 profile.

technique. As a first, mixture of blended powders from each layer and functionally graded samples has been identified by X-ray diffraction technique in order to achieve compare these diffraction patterns with sintered diffraction patterns for the samples. All X-ray diffraction tests are carried out at S.C. of Geological survey and Mining. Low angle $\mathrm{X}$-ray diffraction is performed. $\mathrm{X}$-ray generator with $\mathrm{Cu} \mathrm{Ka}$ radiation at $40 \mathrm{~kW}$ and $20 \mathrm{~mA}$ is used. The target used in the $\mathrm{X}$-ray tube was $\mathrm{Cu}$, therefore $\mathrm{cu}=1.54060^{\circ} \mathrm{A}$ was used in obtaining the XRD patterns.

The X-ray is generated by general electric diffraction type Shimatzo (PW 1840) operating system at scanning speed of $5^{\circ}(2 \theta)$ per minute. The specimen has been held at a fixed angle of $\theta=5$ degrees relative to the case X-ray beam while the detector has motioned through an angle of 2(20-90) degrees.

\section{Results and Discussion}

\section{X-Ray diffraction patterns}

To improve the experimental fabrication of (NiTi) SMA-FGMs, Xray diffractions were made to ensure, that the fabricated alloys in each of SMA-FGMs were transformed homogeneously during the sintering practices. After sintering the samples at $\left(950^{\circ} \mathrm{C}\right)$ for $(7 \mathrm{hrs}$.) under controlled by argon atmosphere, an X-ray diffraction test was done for the sintered SMA-FGMs layer samples as well as whole SMA-FGMs.

The transformation mechanism of shape memory alloys (i.e., layers) is shown in Figure 3. Three specific phases of NiTi are identified for characterization: Martensite (M), Austenite (A), and $\mathrm{Ni}_{3} \mathrm{Ti}$. Nitinol are very sensitive to phase transition temperature according to the compounds of $\mathrm{Ni}$ and Ti. They can have cubic, Monoclinic and Rhombohedral phases according to temperature. It can observe that All Ni and Ti are transformed to NiTi Monoclinic phase and hexagonal $\mathrm{Ni}_{3} \mathrm{Ti}$ phase. The construction of $\mathrm{Ni}_{3} \mathrm{Ti}$ might be referred to the slow cooling of samples inside the furnace [6]. The suggested reactivity during the process are as follows [7].

$$
\begin{array}{lll}
\mathrm{Ni}+\mathrm{Ti} & \rightarrow \mathrm{NiTi} & \Delta \mathrm{G}:-67 \mathrm{KJ} / \mathrm{mol} \\
\mathrm{Ni}+\mathrm{Ti} \rightarrow \mathrm{Ni} 3 \mathrm{Ti} & \Delta \mathrm{G}:-140 \mathrm{KJ} / \mathrm{mol}
\end{array}
$$

The diffraction patterns obtained from the tested samples which the phases, as a result of sintering, could be exposed. From these figures, the Monoclinic phase peaks are observed between $(2 \theta=40-50$ degree). Generally, Nitinol was strongly dependent on composition and thermal treatment, so Ni-Ti alloys can have either a one-step Martensite phase transition from high temperature or a two-step Martensite phase transition.

The sintering temperature applied $\left(950^{\circ} \mathrm{C}\right)$ was about 0.8 of the melting temperature of the NiTi intermetallic component $\left(\mathrm{T}_{\mathrm{m}}=1310^{\circ} \mathrm{C}\right)$, and stock at that temperature for 7 hours under controlled by argon atmosphere will result in complete sintering reaction due to the increase of the inter-diffusion between $\mathrm{Ti}$ and $\mathrm{Ni}$ which in turn leads to 
Citation: Khafaji NSL, Hafiz MH, Atiyah AA (2018) Sintering of Incorporated Shape Memory Alloys into Functionally Graded Materials. Ind Eng Manage S3: 002. doi: 10.4172/2169-0316.S3-002

Page 3 of 4

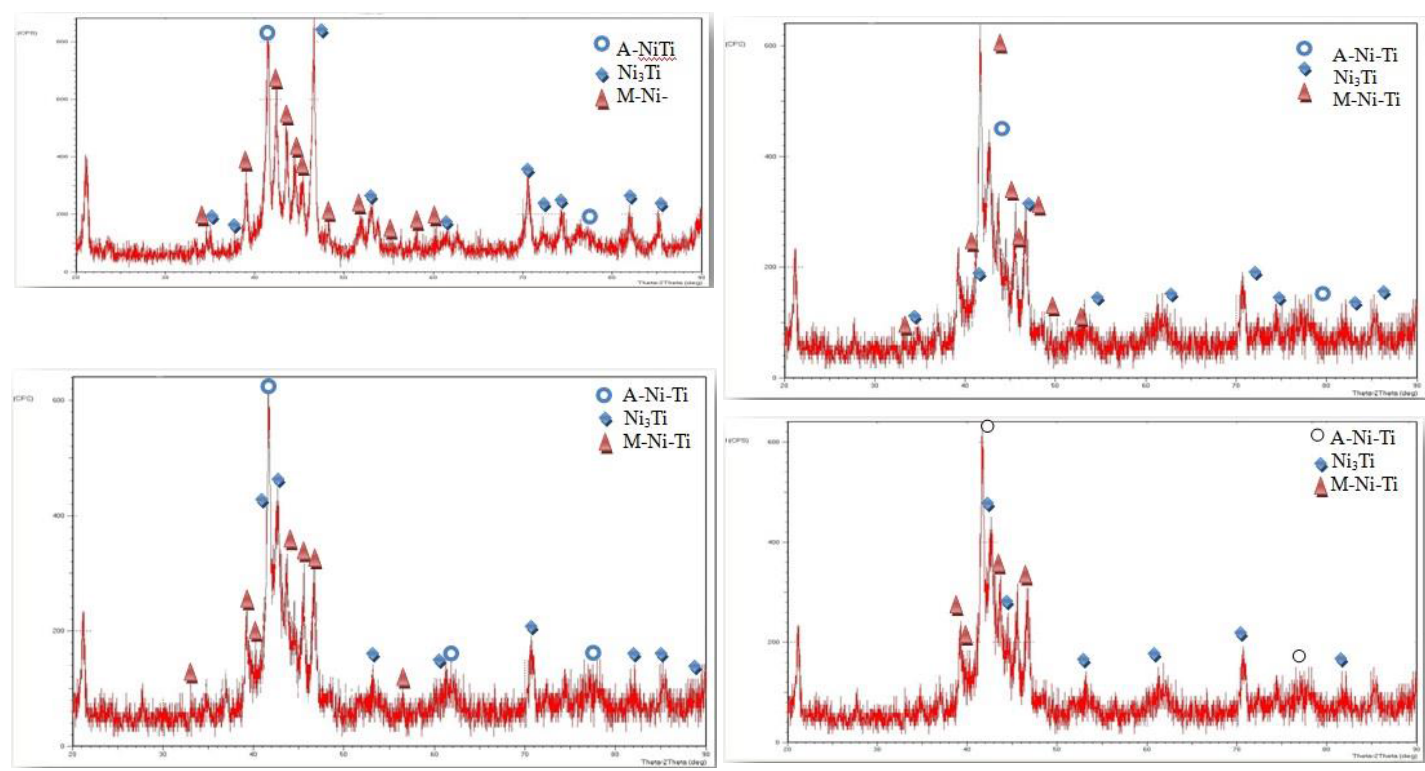

Figure 3: XRD patterns of FGM layers.
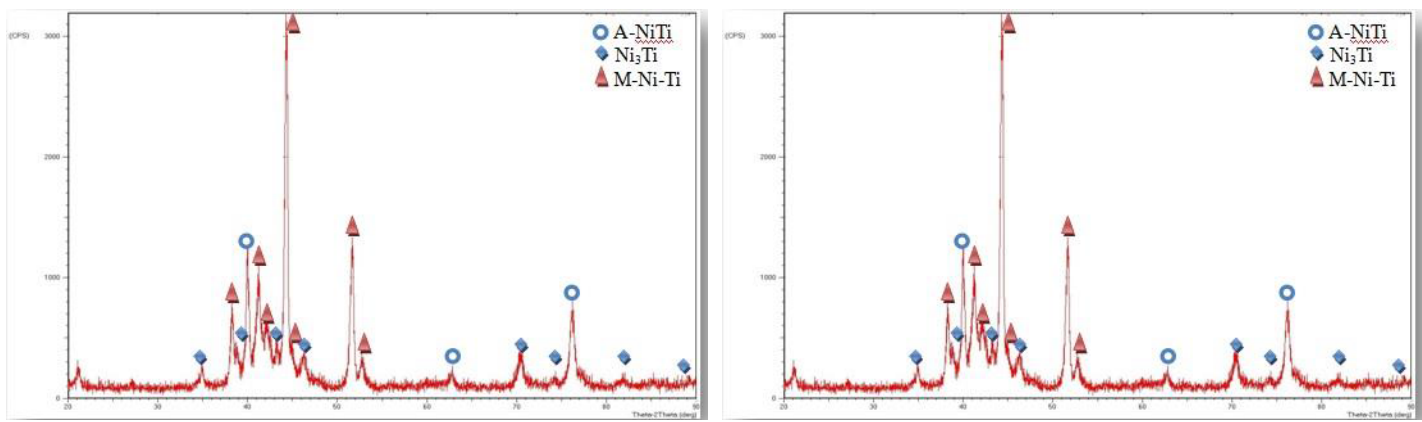

Figure 4: XRD patterns of SMA-FGM1 and SMA-FGM2.

an increase the amount of produced NiTi phase which a major shape memory effect [8].

In other hand, there might have some sort of oxides, which are lower than disclosure ability of the used XRD apparatus when they are less than $5 \%$. The formation of $\mathrm{Ni}_{3} \mathrm{Ti}$ might be refer to the slow cooling of the samples inside furnace whereas, in the sintering conditions used through this work, the Gibbs free energies for $\mathrm{Ni}_{3} \mathrm{Ti}$ was less than that for NiTi and it seems difficult to obtain a final equilibrium structure of $\mathrm{NiTi}$ alone just by solid-state diffusion [9].

There are four (NiTi) alloys have been studied (first, second, third and fourth layers). First layer ( $55 \mathrm{wt} \% \mathrm{Ni}, 45 \mathrm{wt} \% \mathrm{Ti}$ ), its chemical composition is close to that show in Tables 1 and 2, and the other alloys have different chemical composition which is shown also in Tables 1 and 2.

Otherwise, the peaks conformable to $\mathrm{Ni}_{3} \mathrm{Ti}$ might correspond to that view is based on an XRD pattern for a mixture of 50 at\% Ni (50 at $\% \mathrm{Ti}$ ) which shows that the $20 \mathrm{~s}$ (in degrees) in a agreement to angles as shown in Figure 3 [10]. Comparing these angles to those of $\mathrm{Ni}_{3} \mathrm{Ti}$ (Figure 3) one can see that they have nearly the same angles, which makes it difficult to judge (the phases are determined manually, by indicate to reference cards and literatures [11].

Second layer ( $55.8 \mathrm{wt} \% \mathrm{Ni}, 44.2 \mathrm{wt} \% \mathrm{Ti}$ ), its chemical composition, the XRD results can be shown in Figure 3. Third layer $(56.5 \mathrm{wt} \% \mathrm{Ni}$, $43.5 \mathrm{wt} \% \mathrm{Ti})$, its chemical composition, the XRD results can be shown in Figure 3. Forth layer (57.3wt\% Ni, 42.7wt\% Ti), its chemical composition, the XRD results can be shown in Figure 3.

The XRD results for SMA-FGM can be shown in Figure 4. The phases of alloys were specified by calculating $\mathrm{d}$ - spacing (using Brag's law) liken with standard XRD cards. The range of the diffraction angle was $\left(20^{\circ}-90^{\circ}\right)$. All $(\mathrm{Ni}-\mathrm{Ti})$ alloys studied have some phases dependent on chemical composition, the main two phases are (M-NiTi) and $\beta_{2}\left(\mathrm{Ni}_{3} \mathrm{Ti}\right)$, and the other two phases are $\left(\mathrm{Ni}_{2} \mathrm{Ti}\right)$ and $\left(\mathrm{NiTi}_{4}\right)$ [12]. These phases can be detected according to their wt $\%$ used in binary equilibrium phase diagrams for $(\mathrm{Ni}-\mathrm{Ti})$ systems.

\section{Acknowledgments}

The financial support Mr Sattar Radhi Al- Khafaji and the Ministry of Higher Education, is gratefully acknowledged. This research was carried out in the laboratory at Babylon University.

\section{References}

1. Falvo A (2008) Thermomechanical characterization of Nickel-Titanium shape memory alloys. PhD thesis Department of Mechanical Engineering, University Della Calabria. Italy.

2. Koizumi M, Niino M (1995) Overview of FGM research in Japan. Mrs Bulletin 20: $19-21$ 
Citation: Khafaji NSL, Hafiz MH, Atiyah AA (2018) Sintering of Incorporated Shape Memory Alloys into Functionally Graded Materials. Ind Eng Manage S3: 002. doi: 10.4172/2169-0316.S3-002

Page 4 of 4

3. Radhi NS (2015) Preparation, Characterization, and Modeling Functionally Graded Materials in Bio-application. . PhD thesis. University of Technology. Sydney.

4. Markworth AJ, Ramesh KS, Parks WP (1995) Modelling studies applied to functionally graded materials. Journal of Materials Science 30: 2183-2193.

5. Hao YX, Zhang W, Ji XL (2010) Nonlinear dynamic response of functionally graded rectangular plates under different internal resonances. Hindawi Publishing Corporation.

6. Shin HS, Park K, Kim JH, Kim JJ, Han DK, et al. (2009) Biocompatible PEG grafting on DLC-coated nitinol alloy for vascular stents. Journal of Bioactive and Compatible Polymers 24: 316-328.

7. Walker MP, White RJ, Kula KS (2005) Effect of fluoride prophylactic agents on the mechanical properties of nickel-titanium-based orthodontic wires. American
Journal of Orthodontics and Dentofacial Orthopedics 127: 662-669.

8. Li BY, Liyi L (1999) Shape Memory Effect of NiTi alloy. Chinese Academy of Science 42: 96-97.

9. Li BY, Rong LJ, Li YY (1998) Porous NiTi alloy prepared from elemental powder sintering. Journal of Materials Research 13: 2847-2851.

10. Yun LB, Rong LJ (2000) A recent Development in Producing NiTi Shape Memory Alloys. Intermetallics, pp: 881-884.

11. Miyazaki S, Otzuka K, Wayman CM (1998) Medical and Dental Applications of Shape Memory Alloys. Shape Memory Materials Cambridge University, pp: 267-282.

12. Van Humbeeck J, Stalmans R (1998) Characteristics of shape memory alloys. Cambridge University Press, Cambridge, England, pp: 149-183. 